\title{
MULTIUSER BER ANAL YSIS OF CS-QCSK MODULATION SCHEME IN A CELLULAR SYSTEM
}

\author{
K.Thilagam ${ }^{1}$ and K.Jayanthi ${ }^{2}$ \\ ${ }^{1}$ Research Scholar, Department of ECE, Pondicherry Engg. College, Puducherry, India \\ thilagam.k@pec.edu \\ ${ }^{2}$ Associate Professor, Department of ECE, Pondicherry Engg. College, Puducherry,India \\ jayanthi@pec.edu
}

\begin{abstract}
In recent years, chaotic communication is a hot research topic and it suits better for the emerging wireless networks because of its excellent features. Different chaos based modulation schemes have evolved, of which the CS-DCSK modulation technique provides better BER performance and bandwidth efficiency, due to its code domain approach. The QCSK modulation technique provides double benefit: higher data rate with similar BER performance and same bandwidth occupation as DCSK. By combining the advantage of code shifted differential chaos shift keying (CS-DCSK) and Quadrature chaos shift keying (QCSK) scheme, a novel modulation scheme called code shifted Quadrature chaos shift keying (CS-QCSK) is proposed and its suitability in a multiuser scenario is tested in this paper. The analytical expressions for the bit-error rate for Multi-user CS-QCSK scheme (MU-CS-QCSK) under Rayleigh multipath fading channel is derived. The simulation result shows that, in multiuser scenario the proposed method outperforms classical chaotic modulation schemes in terms of bit error rate (BER).
\end{abstract}

\section{KEYWORDS}

Differential chaos shift keying (DCSK) ; Quadrature chaos shift keying (QCSK); Code shifted differential chaos shift keying (CS-DCSK); code shifted Quadrature chaos shift keying ( CS-QCSK); Multiuser code shifted Quadrature chaos shift keying (MU-CS-QCSK); Bit Error Rate(BER).

\section{INTRODUCTION}

In the last few years, a great research effort has been devoted, concerning chaotic carrier modulation. In contrary to the conventional modulation schemes, a wideband, non-periodic chaotic signal is used as carrier, which results in good correlation characteristics and robustness against multipath fading effects. The basic concept of chaos based modulation techniques for coherent and non-coherent systems have been analyzed and studied in [1] \&[2]. For a coherent system, the receiver needs an exact replica of the chaotic signal, such robust synchronization techniques are still not realizable in a practical environment [3].It is worth mentioning the evolution of various types chaos based modulation schemes and their significance and this section is devoted for summarizing the literature survey/ research findings of such schemes. The DCSK scheme, discussed in [4] represents a more robust non-coherent scheme, in which the exact knowledge of the chaotic basis functions is not needed at the receiver. To further enhance the DCSK scheme, frequency-modulated DCSK (FM-DCSK) was introduced to overcome the varying bit-energy problem in DCSK, which is very well explored in [5], [6]. The limitation of the work is that the analysis was purely simulation based with a constant gain channel model.

In [7], the role of synchronization in digital communications using chaos was discussed. At receiver, the two pieces of chaotic signals are correlated, and then the binary symbol is decoded DOI : $10.5121 /$ ijwmn.2012.4611 
International Journal of Wireless \& Mobile Networks (IJWMN) Vol. 4, No. 6, December 2012

based on the sign of the correlator output. The DCSK communication schemes, which exploit the repetitive nature of the chaotic signal, extending from simple binary communications to more sophisticated detectors, have been discussed [8]. In [9], a discrete-time approach for CSK system with multiple users and the multiple-access DCSK (MA-DCSK) system was investigated in depth and a mixed analysis-simulation (MAS) technique was developed to calculate the bit error rates (BERs) using the derived BER analytical expressions. Multipath performance of binary DCSK systems using a standard correlation detector was discussed in [10]-[11]. Quadrature CSK (QCSK) is a multilevel version of DCSK, based on the generation of an orthogonal of chaotic functions. It allows an increase in data rate occupying same bandwidth with respect to DCSK [12]. In [13]-[15], the performance of the DCSK system over a channel with Rayleigh fading and Ricean fading was discussed with the necessity to model the effects of multipath delay spread as well as fading. A multiple-access technique with differential chaos shift keying using a one dimensional iterative map to generate the chaotic signals for all users and similar average data rates for the users have been discussed in [16]-[17]. In [18], the generation of inherent wideband signal with constant energy per bit, which can be achieved by using the combination of frequency modulation with QCSK was discussed. The high-level constellation in FM-QACSK which can improve the speed of chaos shift keying is examined in [19]. In [20], the performance analysis and optimization of multiuser differential chaos shift keying, using dynamically improved gaussian approximation(DIGA) method was discussed.

The DCSK system incorporated with two-user cooperative diversity technique and multiple accessing, using the features of Walsh code sequences was discussed in[21]. It was discussed with the signal structure of chaotic pulse cluster resolving the technical problem and offering a desired solution to multi-user's communication systems using Walsh function division scheme [22]. In[23] a high-efficiency differential chaos shift keying (HEDCSK) with new correlationbased communication scheme, was introduced as an enhanced version of DCSK allowing an increased data rate compared to DCSK with the same bandwidth occupation, but has poor BER performance and bandwidth efficiency. CS-DCSK uses code domain approach, the reference and the information bearing signals are transmitted at the same time slots, it offers bandwidth efficiency but poor BER performance, as discussed in [24]. In [25], the authors discussed that, using the generalized code-shifted DCSK (GCS-DCSK) modulation scheme, the CS-DCSK was extended to transmit multiple bit streams by means of one reference wavelet but has poor BER performance. In [26], a novel chaos based modulation scheme CS-QCSK was proposed and was thoroughly analysed for single user scenario.

In this paper, the analysis of multiuser performance of a novel CS-QCSK modulation scheme is proposed, which is the blend of CS-DCSK and QCSK modulation schemes. In addition to high data rates, it offers the advantage of both the CS-DCSK and QCSK schemes [24], [12]. Analytical expressions for computing BER for the proposed approach has been derived. Further simulation results prove its supremacy over the classical chaos modulation schemes.

The remaining part of the paper is organized as follows: In section 2, conventional schemes and the proposed system model with problem formulation is described. Section 3, elaborates the analytical BER derivation for Rayleigh fading channel. Simulation results are discussed in Section 4. Section 5, deals with the conclusion of the paper.

\section{Overview on ChaOs BaSEd Modulation Schemes}

In order to explain the MU-CS-QCSK system, a brief introduction to DCSK, QCSK, CS-DCSK and CS-QCSK methods is essential and details are given in this section.

\subsection{Differential Chaos Shift Keying (DCSK)}

In DCSK system, for each symbol period, two chaotic sample functions are used to represent, one bit of information [4]. The transmitted DCSK signal has two parts; the first part of the 
signal is the reference signal, while the next part denotes the information-bearing signal. If the bit ' 1 ' is to be transmitted, then the information bearing signal is the replica of the reference part. If the bit ' 0 ' is to be transmitted, then the information bearing signal is the inverted copy of the reference part. The DCSK transmitted symbol can be represented as,

$$
\mathrm{S}_{\text {DCSK }}(\mathrm{t})=\left\{\begin{array}{cc}
\mathrm{x}(\mathrm{t}) & 0 \leq \mathrm{t}<\frac{T}{2} \\
\mp \mathrm{x}(\mathrm{t}-\mathrm{T} / 2) & \frac{T}{2} \leq t<T
\end{array}\right.
$$

where, ' $T$ ' is the symbol duration. In the receiver, the original information is extracted by computing the correlation between two received sample functions. The output of the correlator is sampled over each symbol period and the output is finally given to the decision device to determine the binary values 1 's or 0 's.

\subsection{Quadrature Chaos Shift Keying (QCSK)}

Similar to DCSK method, each symbol period of QCSK also has two parts, but the modification is, information-bearing signals holds two bits of information by means of quadrature chaos shift keying technique. Since two bits of information are transmitted, it is possible for QCSK scheme to obtain higher data rate [12]. Quadrature chaotic signals are produced by an orthonormal basis chaotic sample functions $\mathrm{x}(\mathrm{t})$ and $\mathrm{y}(\mathrm{t})$. Let, $\mathrm{x}(\mathrm{t})$ be the chaotic reference signal, assuming that the signal $\mathrm{x}$ has zero mean value and is defined as

$$
x(t)=\sum_{k=1}^{\infty} f_{k} \sin \left(k \omega t+\varphi_{k}\right)
$$

and let $y(t)$ be the quadrature chaotic reference signal, obtained by changing the phase of each fourier frequency component by $\pi / 2$, and is defined as,

$$
y(t)=\sum_{k=1}^{\infty} f_{k} \sin \left(k \omega t+\varphi_{k}-\pi / 2\right)
$$

The signals $x(t)$ and $y(t)$ are orthogonal in the interval $I_{t}=[0, t]$ and is defined as,

$$
x \perp y \Leftrightarrow \int_{0}^{\tau} x(t) y(t) d t=0
$$

The transmitted QCSK signal is given by,

$\mathrm{S}_{\mathrm{QCSK}}(\mathrm{t})= \begin{cases}\sqrt{E_{b}} \mathrm{c}_{\mathrm{x}}(\mathrm{t}) & 0<\mathrm{t}<\frac{T}{2} \\ \sqrt{E_{b}}\left(\mathrm{a}_{1} \mathrm{c}_{\mathrm{x}}(\mathrm{t}-\mathrm{T} / 2)+\mathrm{a}_{2} \mathrm{c}_{\mathrm{y}}(\mathrm{t}-\mathrm{T} / 2)\right) & \frac{T}{2} \leq t<T\end{cases}$

where $E_{b}$ is the bit energy over $T / 2$ period, satisfying the orthogonal relations.

$C_{x}(t-T / 2)$ is chaotic signal with duration $T / 2$ and $C_{y}(t-T / 2)$ is chaotic signal orthogonal to $C_{x}(t-$ $\mathrm{T} / 2$ ) with same duration of $\mathrm{T} / 2$.

\subsection{Code Shifted - Differential Chaos Shift Keying (CS-DCSK)}

In DCSK, the reference and the information bearing signals are transmitted in two consecutive time slots because of its TDMA approach. This time domain approach requires two independent channels for the transmission of reference and information bearing signals. Further, it requires a delay component both in the modulator and demodulator circuits and halves the data rate. To 
overcome this drawback, an alternative approach used is CS-DCSK, where both the reference and the information bearing signals are transmitted in the same time slot because of its code domain approach (i.e) the two signals are separated by walsh codes instead of time delay [25]. The transmitted CS-DCSK signal is given by,

$$
\mathrm{S}_{C S-D C S K}(\mathrm{t})=\sum_{\mathrm{k}=0}^{N-1} \mathrm{~W}_{\mathrm{R}, \mathrm{k}+1} \mathrm{C}\left(\mathrm{t}-\mathrm{kT}_{\mathrm{c}}\right)+\mathrm{a} \sum_{\mathrm{k}=0}^{\mathrm{N}-1} \mathrm{~W}_{\mathrm{I}, \mathrm{k}+1} \mathrm{C}\left(\mathrm{t}-\mathrm{kT}_{\mathrm{c}}\right)
$$

Where, $\mathrm{T}_{\mathrm{s}}=\mathrm{NT}_{\mathrm{c}}, \mathrm{W}_{\mathrm{R}, \mathrm{k}+1}$ is the reference signal, $\mathrm{W}_{\mathrm{I}, \mathrm{k}+1}$ is the information signal , $\mathrm{C}\left(\mathrm{t}-\mathrm{kT} \mathrm{T}_{\mathrm{c}}\right)$ is the chaotic signal, $T_{s}$ is the symbol duration and $T_{c}$ is the chip duration. The limitation of this system is, with the increased complexity the bit error rate obtained by this system is more or less similar when compared with the existing system.

\subsection{Code Shifted - Quadrature Chaos Shift Keying (CS-QCSK)}

The aforementioned CS-DCSK has poor BER performance and minimum data rate. To overcome this drawback, a novel chaos based modulation scheme Code shifted-Quadrature Chaos Shift Keying (CS-QCSK) is proposed. In this scheme, both the reference and the information bearing signals are transmitted in the same time slot, using walsh codes and the difference is information bearing part holds two bits of information. CS-QCSK can also be said as Hybrid of QCSK and CS-DCSK which will hold the advantage of both the schemes, so that it provides a higher data rate, bandwidth efficiency and better BER performance.The CS-QCSK

transmitted signal is given by,

$$
\mathrm{S}_{C S-Q C S K}(\mathrm{t})=\sum_{k=0}^{N-1} \mathrm{~W}_{\mathrm{R}, \mathrm{k}+1} \mathrm{C}_{\mathrm{x}}\left(\mathrm{t}-\mathrm{k} \mathrm{T}_{\mathrm{c}}\right)+\mathrm{a}_{1} \sum_{k=0}^{\mathrm{N}-1} \mathrm{~W}_{\mathrm{II}, \mathrm{k}+1} \mathrm{C}_{\mathrm{x}}\left(\mathrm{t}-\mathrm{kT}_{\mathrm{c}}\right)+\mathrm{a}_{2} \sum_{k=0}^{\mathrm{N}-1} \mathrm{~W}_{\mathrm{I} 2, \mathrm{k}+1} \mathrm{C}_{\mathrm{y}}\left(\mathrm{t}-\mathrm{kT}_{\mathrm{c}}\right)
$$

Where, $\mathrm{T}_{\mathrm{s}}=\mathrm{NT}_{\mathrm{c}}, \mathrm{W}_{\mathrm{I} 1, \mathrm{k}+1}$ and $\mathrm{W}_{\mathrm{I} 2, \mathrm{k}+1}$ are the information signal, $\mathrm{C}_{\mathrm{x}}\left(\mathrm{t}-\mathrm{k} \mathrm{T}_{\mathrm{c}}\right)$ is the chaotic signal and the $\mathrm{C}_{\mathrm{y}}\left(\mathrm{t}-\mathrm{k} \mathrm{T}_{\mathrm{c}}\right)$ is the orthogonal chaotic signal, $\mathrm{T}_{\mathrm{s}}$ is the symbol duration and $\mathrm{T}_{\mathrm{c}}$ is the chip duration. The limitation of this system is its increased complexity and the performance of the system begins to deteriorate for large number of users. The next section briefly explains the multiuser CS-QCSK system model and its performance analysis in the Rayleigh multipath environment.

\subsection{System Model of Multiuser CS-QCSK Modulation}

The aim of this section is to illustrate the practical importance of CS-QCSK modulation scheme, whose simplified transmitter and receiver block diagram are shown in figures 1 and 2 respectively. A baseband system is considered for simplicity. But it is understood, that if the scheme is to be employed for wireless communications a modulator is in need to generate the corresponding RF passband signal. Furthermore, it is assumed that the description of the MUCS-QCSK scheme in the continuous-time domain admits an equivalent discrete-time representation. From the earlier stated discussions, it can be concluded that, by combining CSDCSK and QCSK schemes, a novel CS-QCSK modulation scheme can be realised and it is thoroughly analysed in the presence of multiple users.

\subsubsection{Transmitter}

In MU-CS-QCSK system, the symbol ' $S$ ' is transmitted with the reference signal and information signal in the same time slot but separated by Walsh code sequences. Let there be ' $\mathrm{N}_{\mathrm{u}}$ ' number of users.

The MU-CS-QCSK transmitted signal is given by,

$$
\mathrm{S}_{M}(\mathrm{t})=\sum_{k=0}^{N-1} \mathrm{~W}_{\mathrm{R}, \mathrm{k}+1} \mathrm{C}_{\mathrm{x}}\left(\mathrm{t}-\mathrm{kT} \mathrm{T}_{\mathrm{c}}\right)+\sum_{u=1}^{N_{u}}\left[a_{1 u} \sum_{k=0}^{\mathrm{N}-1} \mathrm{~W}_{\mathrm{IIl}, \mathrm{k}+1} \mathrm{C}_{\mathrm{x}}\left(\mathrm{t}-\mathrm{kT}_{\mathrm{c}}\right)+a_{2 u} \sum_{k=0}^{\mathrm{N}-1} \mathrm{~W}_{\mathrm{I} 2 u, \mathrm{k}+1} \mathrm{C}_{\mathrm{y}}\left(\mathrm{t}-\mathrm{kT}_{\mathrm{c}}\right)\right]
$$


International Journal of Wireless \& Mobile Networks (IJWMN) Vol. 4, No. 6, December 2012

Where, $\mathrm{T}_{\mathrm{s}}=\mathrm{NT}_{\mathrm{c},} \mathrm{a}_{1 \mathrm{u}} \in\{-1,1\}, \mathrm{a}_{2 \mathrm{u}} \in\{-1,1\}$ is mapped from $\mathrm{b} \in\{0,1\}$ which is the information bit to be transmitted. This scheme uses different Walsh code for the reference and information signal, where $\mathrm{W}_{\mathrm{R}, \mathrm{k}+1}$ represent the Walsh code for reference signal and $\mathrm{W}_{\mathrm{Il} u, k+1}, \mathrm{~W}_{\mathrm{ILu}, \mathrm{k}+1}$ represent the Walsh code for the two consecutive information bits, $\mathrm{C}(\mathrm{t})$ is the chaotic signal with duration of $T_{c}$ and $u=1, \ldots ., N_{u}$ represents the number of users in the system. Both the reference and the information signal are transmitted in the same time slot as given in equation (8). The orthogonality of two signals are given by,

$$
\begin{gathered}
\mathrm{C}_{\mathrm{x}}\left(\mathrm{t}-\mathrm{kT}_{\mathrm{c}}\right)=\left\{\begin{array}{cc}
\mathrm{c}_{\mathrm{x}}(\mathrm{t}) & \mathrm{kT}_{\mathrm{c}} \leq \mathrm{t}<(k+1) \mathrm{T}_{\mathrm{c}} \\
0 & \text { otherwise }
\end{array}\right. \\
\mathrm{C}_{\mathrm{y}}\left(\mathrm{t}-\mathrm{kT}_{\mathrm{c}}\right)=\left\{\begin{array}{cc}
\mathrm{c}_{\mathrm{y}}(\mathrm{t}) & \mathrm{kT}_{\mathrm{c}} \leq \mathrm{t}<(k+1) \mathrm{T}_{\mathrm{c}} \\
0 & \text { otherwise }
\end{array}\right.
\end{gathered}
$$

Let,

$$
\begin{aligned}
& \Delta=\int_{0}^{T_{s=N T_{c}}} \sum_{k=0}^{N-1} \mathrm{~W}_{\mathrm{R}, \mathrm{k}+1} \mathrm{C}_{\mathrm{x}}\left(\mathrm{t}-\mathrm{kT}_{\mathrm{c}}\right) \mathrm{a}_{1 u} \sum_{k=0}^{\mathrm{N}-1} \mathrm{~W}_{\mathrm{I} l u, \mathrm{k}+1} \mathrm{C}_{\mathrm{x}}\left(\mathrm{t}-\mathrm{kT}_{\mathrm{c}}\right) \mathrm{a}_{2 u} \sum_{k=0}^{\mathrm{N}-1} \mathrm{~W}_{\mathrm{I} 2 u, \mathrm{k}+1} \mathrm{C}_{\mathrm{y}}\left(\mathrm{t}-\mathrm{kT}_{\mathrm{c}}\right) \cdot d t \\
& E_{b}=\int_{0}^{T_{\mathrm{t}}} c^{2}(t) c_{y}(t) \cdot d t
\end{aligned}
$$

$(.)^{T}=$ Transporse of vector.

$\mathrm{c}_{\mathrm{x}}(\mathrm{t})=\mathrm{C}_{\mathrm{x}}\left(\mathrm{t}-\mathrm{kT}_{\mathrm{c}}\right) ; \forall k$

$\mathrm{c}_{y}(\mathrm{t})=\mathrm{C}_{y}\left(\mathrm{t}-\mathrm{kT}_{\mathrm{c}}\right) ; \forall k$

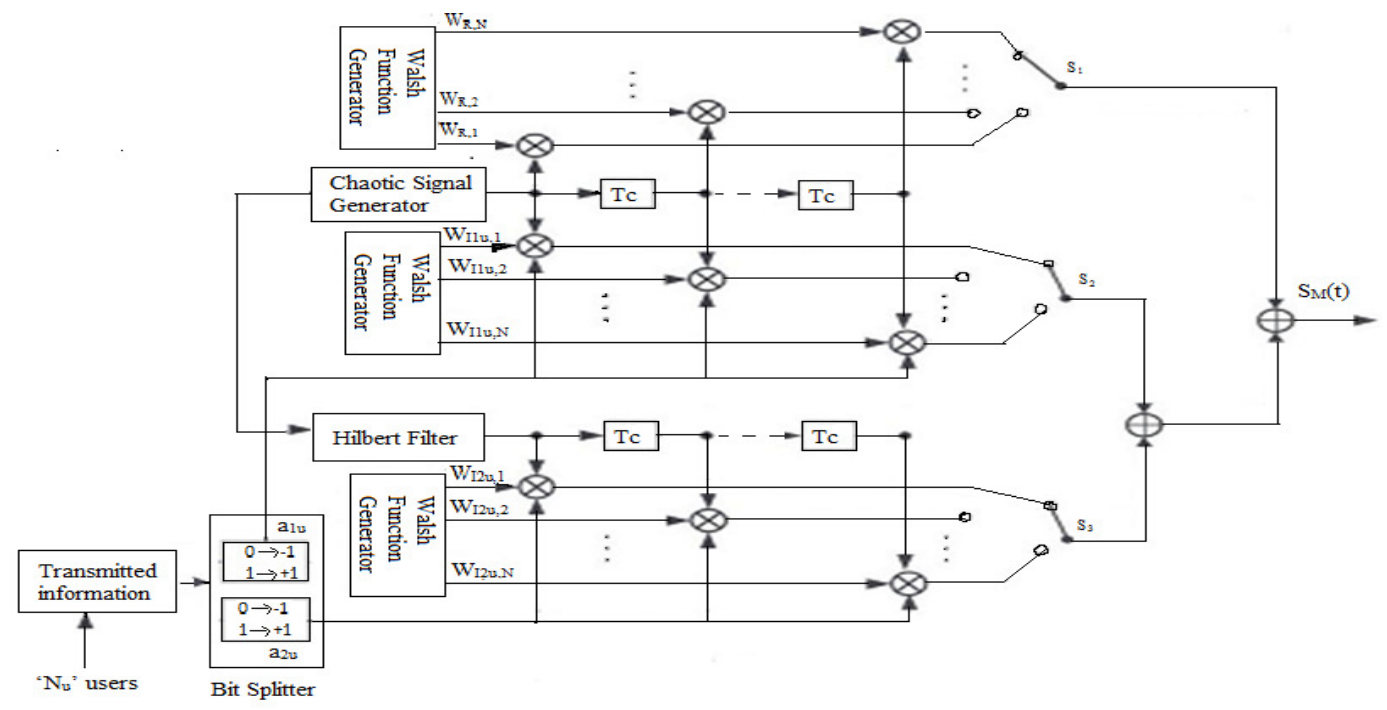

Figure 1. Block diagram of Multiuser CS-QCSK Transmitter

Referring to the transmitter block diagram of figure 1, the CS-QCSK modulation scheme consist of chaos signal generator, which generates chaos signal $C_{x}(t)$ and its orthogonal signal $\mathrm{C}_{\mathrm{y}}(\mathrm{t})$. The orthogonal signal is obtained by taking the Hilbert transform of the chaos signal $\mathrm{C}_{\mathrm{x}}$ $(\mathrm{t})$. The transmitter block consists of three Walsh function generator, which generates three different Walsh code sequences that are orthogonal in nature. It has $(\mathrm{N}-1)$ delay elements of $\mathrm{T}_{\mathrm{c}}$ 
International Journal of Wireless \& Mobile Networks (IJWMN) Vol. 4, No. 6, December 2012

chip duration. The three Walsh function generator, generate Walsh codes, $\mathrm{W}_{\mathrm{R}, \mathrm{k}+1}$ for reference signal, and $\mathrm{W}_{\mathrm{Ilu}, \mathrm{k}+1}, \mathrm{~W}_{\mathrm{I} 2 \mathrm{u}, \mathrm{k}+1}$ for information signal for ' $\mathrm{u}$ ' users, where, $\mathrm{u}=1, \ldots . \mathrm{Nu}$. The reference signal of Walsh code $\mathrm{W}_{\mathrm{R}, \mathrm{k}+1}$ is multiplied with the chaos signal and the corresponding output is obtained by the switching unit S1.It has a bit splitter, which splits the input bit stream into odd and even sequences. The first information signal of the $u^{\text {th }}$ user's Walsh code ' $W_{\mathrm{Ilu}, \mathrm{k}+1}$ ' is multiplied with the odd sequence of bits and the chaos signal ,the corresponding output is obtained by the switching unit $S_{2}$. The second information signal of the $u^{\text {th }}$ user's walsh code ' $\mathrm{W}_{\mathrm{I} 2 \mathrm{u}, \mathrm{k}+1}$ ' is multiplied with the even sequence of bits and the orthogonal chaos signal, the corresponding output is obtained by the switching unit $\mathrm{S}_{3}$. The output obtained at the switching unit $S_{2}$ and $S_{3}$ are summed for ' $u$ ' users and it is further summed with the switching unit $S 1$ to obtain the final output. The composite CS-QCSK signal is finally obtained.

\subsubsection{Receiver}

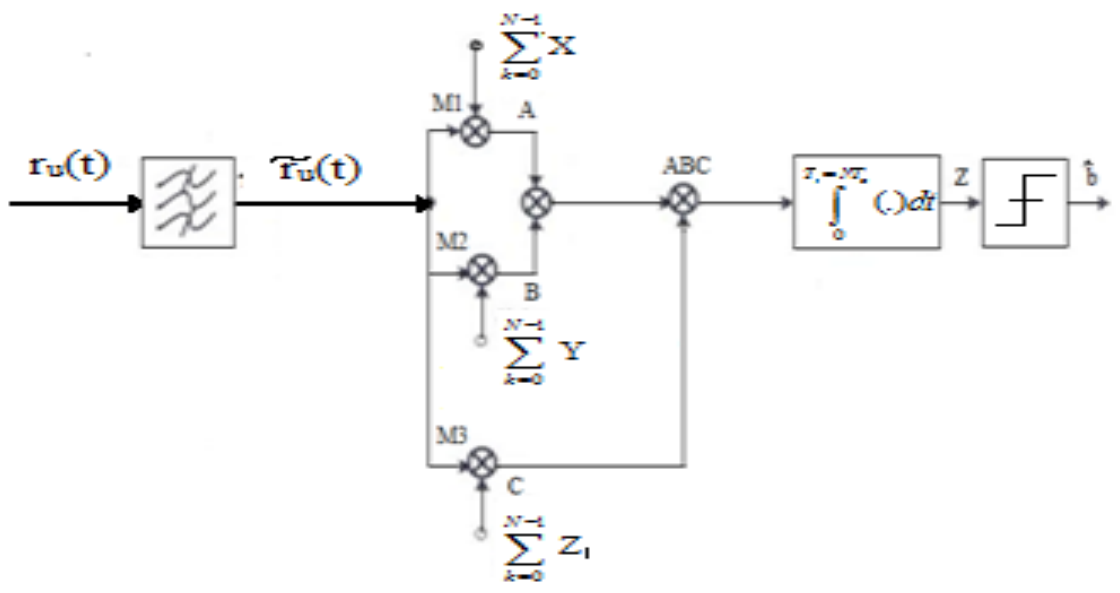

Figure 2. Block diagram of MU-CS-QCSK Receiver

Figure 2. shows the possible hardware realisation of MU-CS-QCSK receiver. The receiver unit consists of band pass filter with the bandwidth of $2 B$ which can pass the received signal $r_{u}(t)$ without any distortion. The receiver filter output with Additive White Gaussian Noise (AWGN) $\mathrm{n}(\mathrm{t})$ is obtained as

$$
\begin{aligned}
& r_{u}(t)=\sum_{k=0}^{N-1} \mathrm{~W}_{\mathrm{R}, \mathrm{k}+1} \mathrm{C}_{\mathrm{x}}\left(\mathrm{t}-\mathrm{kT}_{\mathrm{c}}\right)+\sum_{k=0}^{N}\left[\mathrm{a}_{1 u} \sum_{k=0}^{\mathrm{N}-1} \mathrm{~W}_{\mathrm{Il} u, \mathrm{k}+1} \mathrm{C}_{\mathrm{x}}\left(\mathrm{t}-\mathrm{kT}_{\mathrm{c}}\right)+\mathrm{a}_{2 u} \sum_{k=0}^{\mathrm{N}-1} \mathrm{~W}_{\mathrm{I} 2 u, \mathrm{k}+1} \mathrm{C}_{\mathrm{y}}\left(\mathrm{t}-\mathrm{kT}_{\mathrm{c}}\right)\right]+\mathrm{n}(\mathrm{t})(10) \\
& \operatorname{rect}_{\mathrm{x}}\left(\mathrm{t}-\mathrm{kT}_{\mathrm{c}}\right)= \begin{cases}1 & , \mathrm{kT}_{\mathrm{c}} \leq \mathrm{t}<(k+1) \mathrm{T}_{\mathrm{c}} \\
0 & , \text { otherwise }\end{cases} \\
& \operatorname{rect}_{\mathrm{y}}\left(\mathrm{t}-\mathrm{kT}_{\mathrm{c}}\right)=\left\{\begin{array}{cc}
1 & , \mathrm{kT}_{\mathrm{c}} \leq \mathrm{t}<(k+1) \mathrm{T}_{\mathrm{c}} \\
0 & , \text { otherwise }
\end{array}\right.
\end{aligned}
$$

Let,

$$
\mathrm{X}=\mathrm{W}_{R, \mathrm{k}+1} \operatorname{rect}_{\mathrm{x}}\left(\mathrm{t}-\mathrm{kT}_{\mathrm{c}}\right), \mathrm{Y}=\mathrm{W}_{\mathrm{Ilu}, \mathrm{k}+1} \operatorname{rect}_{\mathrm{x}}\left(\mathrm{t}-\mathrm{kT}_{\mathrm{c}}\right), \mathrm{Z}_{1}=\mathrm{W}_{\mathrm{I} 2 u, \mathrm{k}+1} \text { rect }_{y}\left(\mathrm{t}-\mathrm{kT}_{\mathrm{c}}\right) \text { and }
$$

Let,

$$
\mathrm{A}=S_{M}(\mathrm{t}) \sum_{k=0}^{N-1} \mathrm{~W}_{R, \mathrm{k}+1} \text { rect }_{\mathrm{x}}\left(\mathrm{t}-\mathrm{kT}_{\mathrm{c}}\right)
$$




$$
\begin{aligned}
& \mathrm{B}=S_{M}(\mathrm{t}) \sum_{k=0}^{N-1} \mathrm{~W}_{\mathrm{Ilu}, \mathrm{k}+1} \operatorname{rect}_{\mathrm{x}}\left(\mathrm{t}-\mathrm{kT}_{\mathrm{c}}\right) \\
& C=S_{M}(\mathrm{t}) \sum_{k=0}^{N-1} \mathrm{~W}_{\mathrm{I} 2 u, \mathrm{k}+1} \operatorname{rect}_{\mathrm{y}}\left(\mathrm{t}-\mathrm{kT}_{\mathrm{c}}\right)
\end{aligned}
$$

The integrator output is thus,

$$
Z=\int_{0}^{T_{s}=N T_{c}} A B C \cdot d t
$$

Substituting, equation (8) in (11),(12)and(13). The equations (15), (16) and (17) are obtained.

$$
\begin{aligned}
& \mathrm{A}=\sum_{k=0}^{N-1} \mathrm{C}_{\mathrm{x}}\left(\mathrm{t}-\mathrm{kT}_{\mathrm{c}}\right)+\mathrm{a}_{1 u} \sum_{k=0}^{\mathrm{N}-1} \mathrm{~W}_{\mathrm{R}, \mathrm{k}+1} \mathrm{~W}_{\mathrm{Il} u, \mathrm{k}+1} \mathrm{C}_{\mathrm{x}}\left(\mathrm{t}-\mathrm{kT}_{\mathrm{c}}\right)+\mathrm{a}_{2 u} \sum_{k=0}^{\mathrm{N}-1} \mathrm{~W}_{\mathrm{R}, \mathrm{k}+1} \mathrm{~W}_{\mathrm{I} 2 u, \mathrm{k}+1} \mathrm{C}_{\mathrm{y}}\left(\mathrm{t}-\mathrm{kT}_{\mathrm{c}}\right) \\
& \mathrm{B}=\sum_{\mathrm{k}=0}^{\mathrm{N}-1} \mathrm{~W}_{\mathrm{R}, \mathrm{k}+1} \mathrm{~W}_{\mathrm{I} 1 u, \mathrm{k}+1} \mathrm{C}_{\mathrm{x}}\left(\mathrm{t}-\mathrm{kT}_{\mathrm{c}}\right)+\mathrm{a}_{1 u} \sum_{\mathrm{k}=0}^{N-1} \mathrm{C}_{\mathrm{x}}\left(\mathrm{t}-\mathrm{kT}_{\mathrm{c}}\right) \\
& \mathrm{C}=\sum_{\mathrm{k}=0}^{\mathrm{N}-1} \mathrm{~W}_{\mathrm{R}, \mathrm{k}+1} \mathrm{~W}_{\mathrm{I} 2 u, \mathrm{k}+1} \mathrm{C}_{\mathrm{x}}\left(\mathrm{t}-\mathrm{kT}_{\mathrm{c}}\right)+\mathrm{a}_{2 u} \sum_{\mathrm{k}=0}^{N-1} \mathrm{C}_{\mathrm{y}}\left(\mathrm{t}-\mathrm{kT}_{\mathrm{c}}\right)
\end{aligned}
$$

Substituting equation (14), (15) and (16) in (13), the observation vector ' $Z$ ' is obtained as,

$$
\begin{aligned}
& Z=\int_{0}^{T_{s}=N T_{c}}\left(\sum_{\mathrm{k}=0}^{N-1} \mathrm{C}_{\mathrm{x}}\left(\mathrm{t}-\mathrm{kT}_{\mathrm{c}}\right)+\mathrm{a}_{1 u} \sum_{\mathrm{k}=0}^{\mathrm{N}-1} \mathrm{~W}_{\mathrm{R}, \mathrm{k}+1} \mathrm{~W}_{\mathrm{II} u, \mathrm{k}+1} \mathrm{C}_{\mathrm{x}}\left(\mathrm{t}-\mathrm{kT}_{\mathrm{c}}\right)+\mathrm{a}_{2 u} \sum_{\mathrm{k}=0}^{\mathrm{N}-1} \mathrm{~W}_{\mathrm{R}, \mathrm{k}+1} \mathrm{~W}_{\mathrm{I} 2 u, \mathrm{k}+1} \mathrm{C}_{\mathrm{y}}\left(\mathrm{t}-\mathrm{kT}_{\mathrm{c}}\right)\right) . \\
& \left(\sum_{\mathrm{k}=0}^{\mathrm{N}-1} \mathrm{~W}_{\mathrm{R}, \mathrm{k}+1} \mathrm{~W}_{\mathrm{II} u, \mathrm{k}+1} \mathrm{C}_{\mathrm{x}}\left(\mathrm{t}-\mathrm{kT}_{\mathrm{c}}\right)+\mathrm{a}_{1 u} \sum_{\mathrm{k}=0}^{N-1} \mathrm{C}_{\mathrm{x}}\left(\mathrm{t}-\mathrm{kT}_{\mathrm{c}}\right)\right)\left(\sum_{\mathrm{k}=0}^{\mathrm{N}-1} \mathrm{~W}_{\mathrm{R}, \mathrm{k}+1} \mathrm{~W}_{\mathrm{I} 2 u, \mathrm{k}+1} \mathrm{C}_{\mathrm{x}}\left(\mathrm{t}-\mathrm{kT}_{\mathrm{c}}\right)+\mathrm{a}_{2 u} \sum_{\mathrm{k}=0}^{N-1} \mathrm{C}_{\mathrm{y}}\left(\mathrm{t}-\mathrm{kT}_{\mathrm{c}}\right)\right) d t
\end{aligned}
$$

The above equation (18) can be simplified as,

$$
Z \cong a_{1 u} a_{2 u} E_{b}
$$

\section{BER ANALYSIS FOR MULTIPATH RAYLEIGH FADING SCENARIO}

The analytical expression for the BER of MU-CS-QCSK under the multipath Rayleigh fading channel is derived in the following section to validate the simulated results.

\subsection{Multipath Rayleigh fading Channels}

From the receiver unit, the obtained observation variable ' $Z$ ' is given by

$$
\mathrm{Z}=\sum_{k=0}^{N-1} \int_{\mathrm{k} \mathrm{T}_{\mathrm{c}}}^{(\mathrm{k}+1) \mathrm{T}_{\mathrm{c}}}\left[\mathrm{W}_{\mathrm{R}, \mathrm{k}+1} \cdot{ }_{r}^{\sim}(t)\right]\left[\mathrm{W}_{\mathrm{I} 1 u, \mathrm{k}+1} \mathrm{~W}_{\mathrm{I} 2 u, \mathrm{k}+1} \cdot{ }_{r}^{\sim}(t)\right] \mathrm{dt}
$$


International Journal of Wireless \& Mobile Networks (IJWMN) Vol. 4, No. 6, December 2012

$=\sum_{\mathrm{k}=0}^{\mathrm{N}-1} \mathrm{~W}_{\mathrm{R}, \mathrm{k}+1} \mathrm{~W}_{\mathrm{Il} u, \mathrm{k}+1} \mathrm{~W}_{\mathrm{I} 2 u, \mathrm{k}+1} \int_{\mathrm{kT}}^{(\mathrm{k}+1) \mathrm{T}_{c}}\left[\left(\mathrm{~W}_{\mathrm{R}, \mathrm{k}+1}+\sum_{u=1}^{N_{u}} \mathrm{a}_{1 u} \mathrm{~W}_{\mathrm{Il} u, \mathrm{k}+1}+\sum_{u=1}^{N_{u}} \mathrm{a}_{2 u} \mathrm{~W}_{\mathrm{I} 2 u, \mathrm{k}+1}\right) \cdot c\left(t-k T_{c}\right)+n(t)\right]^{2} \cdot d t$

There are different types of chaotic maps to generate the chaotic signals, they are classified as (i)logistic map (ii) cubic map (iii) Bernoulli-shift map. In the proposed method, logistic map is considered and is defined as, $x(n+1)=1-2 x^{2}(n)$. Where, $\beta=T_{c} f_{s}$ is the number of samples in a chip time and $\mathrm{K}=\mathrm{T}_{\mathrm{s}} \mathrm{f}_{\mathrm{s}}=\mathrm{N} \beta$ is the symbol duration. In the remaining part of the paper, ' $\mathrm{K}$ ' is referred as the spreading factor. Consider, the transmission of $\mathrm{a}_{1 \mathrm{u}}=\mathrm{a}_{2 \mathrm{u}}=+1$ sequence. The logistic map is defined in the continuous time domain. In order to convert into the discrete time domain, consider $C_{j}$ to be the samples of chaotic signal and $\eta_{j}$ be its corresponding channel noise. Then, ' $\mathrm{Z}$ ' the equation for discrete time equivalent is defined as,

$Z=\sum_{\mathrm{k}=0}^{\mathrm{N}-1} \mathrm{~W}_{\mathrm{R}, \mathrm{k}+1} \mathrm{~W}_{\mathrm{I} 1 u, \mathrm{k}+1} \mathrm{~W}_{\mathrm{I} 2 u, \mathrm{k}+1} \sum_{\mathrm{m}=1}^{\beta}\left[\left(\mathrm{W}_{\mathrm{R}, \mathrm{k}+1}+\mathrm{a}_{1 u} \mathrm{~W}_{\mathrm{I} 1, \mathrm{k}+1}+\mathrm{a}_{2 u} \mathrm{~W}_{\mathrm{I} 2 u, \mathrm{k}+1}\right) \cdot c_{k \beta+m}+\eta_{k \beta+m}\right]^{2}$

Where,

$c_{k \beta+m}=\left\{\begin{array}{lr}c_{m} & , \kappa \beta \leq \kappa \beta+m<(k+1) \beta \\ 0 & \text {, otherwise }\end{array}\right.$

From the equation (22), the decision variable is decomposed into three terms,

$$
Z=Z_{A}+Z_{B}+Z_{C}
$$

where,

$$
\begin{aligned}
& Z_{A}=\sum_{\mathrm{k}=0}^{\mathrm{N}-1} \mathrm{~W}_{\mathrm{R}, \mathrm{k}+1} \mathrm{~W}_{\mathrm{I} 1 u, \mathrm{k}+1} \mathrm{~W}_{\mathrm{I} 2 u, \mathrm{k}+1} \sum_{\mathrm{m}=1}^{\beta}\left[\left(\mathrm{W}_{\mathrm{R}, \mathrm{k}+1}+\mathrm{a}_{1 u} \mathrm{~W}_{\mathrm{I} 1 u, \mathrm{k}+1}+\mathrm{a}_{2 u} \mathrm{~W}_{\mathrm{I} 2 u, \mathrm{k}+1}\right)^{2}\left(c_{k \beta+m}\right)^{2}\right] \\
& Z_{B}=\sum_{\mathrm{k}=0}^{\mathrm{N}-1} \mathrm{~W}_{\mathrm{R}, \mathrm{k}+1} \mathrm{~W}_{\mathrm{I} l u, \mathrm{k}+1} \mathrm{~W}_{\mathrm{I} 2 u, \mathrm{k}+1} \sum_{\mathrm{m}=1}^{\beta}\left[\left(\mathrm{W}_{\mathrm{R}, \mathrm{k}+1}+\mathrm{a}_{1 u} \mathrm{~W}_{\mathrm{I} 1 u, \mathrm{k}+1}+\mathrm{a}_{2 u} \mathrm{~W}_{\mathrm{I} 2 u, \mathrm{k}+1}\right)\left(c_{k \beta+m}\right)\left(\eta_{k \beta+m}\right)\right] \\
& Z_{C}=\sum_{\mathrm{k}=0}^{\mathrm{N}-1} \mathrm{~W}_{\mathrm{R}, \mathrm{k}+1} \mathrm{~W}_{\mathrm{I} 1 u, \mathrm{k}+1} \mathrm{~W}_{\mathrm{I} 2 u, \mathrm{k}+1} \sum_{\mathrm{m}=1}^{\beta}\left(c_{k \beta+m}\right)^{2}
\end{aligned}
$$

By applying, expectation and variance to the above equations, the expectation and variance values of these variables are obtained as follows:

$$
\begin{aligned}
& E\left\{Z_{A} \mid b=1\right\}=E\left\{Z_{A} \mid a=+1\right\}=3 N \beta+\frac{1}{2} N \beta\left[N_{u}^{2}\left(N_{u}+1\right)^{2}\right] E\left\{C_{j}^{2}\right\} \\
& E\left\{Z_{B} \mid b=1\right\}=E\left\{Z_{B} \mid a=+1\right\}=0 \\
& E\left\{Z_{C} \mid b=1\right\}=E\left\{Z_{C} \mid a=+1\right\}=0 \\
& \operatorname{Var}\left\{Z_{A} \mid b=1\right\}=\operatorname{Var}\left\{Z_{A} \mid a=+1\right\}=9 N^{2} \beta^{2}+\frac{7}{4} N^{2} \beta^{2} N_{u}^{6} \operatorname{Var}\left\{C_{j}^{2}\right\}
\end{aligned}
$$


International Journal of Wireless \& Mobile Networks (IJWMN) Vol. 4, No. 6, December 2012

$$
\begin{aligned}
& \operatorname{Var}\left\{Z_{B} \mid b=1\right\}=\operatorname{Var}\left\{Z_{B} \mid a=+1\right\}=4 N^{2} \beta^{2} N_{0}^{2} N_{u}^{2}\left(N_{u}+1\right)^{2} \operatorname{Var}\left\{C_{j}^{2}\right\} \\
& \operatorname{Var}\left\{Z_{C} \mid b=1\right\}=\operatorname{Var}\left\{Z_{C} \mid a=+1\right\}=N \beta N_{0}^{2}
\end{aligned}
$$

Where, $\mathrm{E}\{$.$\} represents the expectation operator and \operatorname{var}\{$.$\} represents the variance operator$ ,then

$$
\begin{aligned}
& E\{Z \mid b=1\}=E\{Z \mid a=+1\}=3 N \beta+\frac{1}{2} N \beta\left[N_{u}^{2}\left(N_{u}+1\right)^{2}\right] E\left\{C_{j}^{2}\right\} \\
& \operatorname{Var}\{Z \mid b=1\}=\operatorname{Var}\{Z \mid a=+1\}=9 N^{2} \beta^{2}+\frac{7}{4} N^{2} \beta^{2} N_{u}^{6} \operatorname{Var}\left\{C_{j}^{2}\right\}+4 N^{2} \beta^{2} N_{0}^{2} N_{u}^{2}\left(N_{u}+1\right)^{2} \operatorname{Var}\left\{C_{j}^{2}\right\}+N \beta N_{0}^{2}
\end{aligned}
$$

For the transmission of ' $\mathrm{a}_{1 \mathrm{u}}=\mathrm{a}_{2 \mathrm{u}}=-1$ ' sequence, the expectation and variance of observation variable is derived similarly.

$$
\begin{aligned}
& E\{Z \mid a=-1\}=-E\{Z \mid a=+1\} \\
& \operatorname{Var}\{Z \mid a=-1\}=\operatorname{Var}\{Z \mid a=+1\}
\end{aligned}
$$

It is assumed, that the probability distribution of the observation variable can be approximated and the transmitted bits are equiprobable. Therefore, the bit error rate of MU-CS-QCSK modulation scheme is obtained as,

$$
\begin{aligned}
& \text { BER }=\frac{1}{2} \operatorname{Pr}\left(Z_{m u}<0 \mid b=1\right)+\frac{1}{2} \operatorname{Pr}\left(Z_{m u} \geq 0 \mid b=0\right) \\
& =\frac{1}{2} \operatorname{Pr}\left(Z_{m u}<0 \mid a=+1\right)+\frac{1}{2} \operatorname{Pr}\left(Z_{m u} \geq 0 \mid a=-1\right) \\
& =\frac{1}{2} \operatorname{erfc}\left(\frac{E\left\{Z_{m u} \mid a=+1\right\}}{\sqrt{2 \operatorname{Var}\left\{Z_{m u} \mid a=+1\right\}}}\right)
\end{aligned}
$$

Where, $\mathrm{m}=2$; represents the number of information bits transmitted per time slot and $\mathrm{u}=1, \ldots, \mathrm{Nu}$; represents the number of users. For logistic maps, the expectation of chaos signal is $E\left\{C_{j}^{2}\right\}=1 / 2$ and variance of chaos signal is $\operatorname{Var}\left\{C_{j}^{2}\right\}=1 / 8$. By substituting, the expectation values in the numerator and variance values in the denominator in the above equation, it becomes

$$
=\frac{1}{2} \operatorname{erfc}\left(\frac{3 N \beta+\frac{1}{2} N \beta\left[N_{u}^{2}\left(N_{u}+1\right)^{2}\right] E\left\{C_{j}^{2}\right\}}{\sqrt{2\left(9 N^{2} \beta^{2}+\frac{7}{4} N^{2} \beta^{2} N_{u}^{6} \operatorname{Var}\left\{C_{j}^{2}\right\}+4 N^{2} \beta^{2} N_{0}^{2} N_{u}^{2}\left(N_{u}+1\right)^{2} \operatorname{Var}\left\{C_{j}^{2}\right\}+N \beta N_{0}^{2}\right)}}\right)
$$

The conditional BER measured for the multipath channel is given by,

$\operatorname{BER}\left(\alpha_{0}, \alpha_{1 \ldots \ldots \ldots . . .} \alpha_{\mathrm{L}-1}\right)=\operatorname{BER}\left(\gamma_{\mathrm{b}}\right)$

Where, $\gamma_{\mathrm{b}}=\left(\mathrm{E}_{\mathrm{b}} / \mathrm{N}_{\mathrm{o}}\right)\left(\alpha_{0}, \alpha_{1} \ldots \ldots \ldots . \alpha_{\mathrm{L}-1}\right)=\left(\gamma_{0}+\gamma_{1}+\ldots \ldots \ldots \ldots \ldots+\gamma_{\mathrm{L}-1}\right)$. 
International Journal of Wireless \& Mobile Networks (IJWMN) Vol. 4, No. 6, December 2012

Let, $\mathrm{L}$ be the number of propagation paths, ' $\alpha_{1}$ ' be the gain of the $1^{\text {th }}$ path, $\tau_{1}$ be the delay of the $1^{\text {th }}$ path. The gains $\alpha_{1}$ of the propagation paths is assumed to be independent identical distributed Rayleigh random variables. The probability density function (PDF) of $\gamma_{i}$ is an exponential distribution given by,

$$
f(x)=\frac{1}{\gamma_{k}} \exp \left(\frac{-x}{\gamma_{k}}\right)
$$

The probability density function (pdf) of $\gamma_{\mathrm{b}}$ is obtained as,

$$
f\left(\gamma_{\mathrm{b}}\right)=f\left(\gamma_{0}\right) \otimes f\left(\gamma_{1}\right) \ldots \ldots \ldots \ldots \otimes f\left(\gamma_{L-1}\right)
$$

Where, $f\left(\gamma_{\mathrm{k}}\right)$ is the pdf of instantaneous (SNR) measured in the ith path. By averaging the conditional bit error rates in the multipath channels, the total BER measured is obtained as,

$$
B E R=\int_{0}^{\infty} B E R\left(\gamma_{\mathrm{b}}\right) f\left(\gamma_{\mathrm{b}}\right) d \gamma_{\mathrm{b}}
$$

It is assumed to have two propagation paths, and then the bit error rate expressions for Multiuser CS-QCSK (MU-CS-QCSK) can be simplified as,

$$
B E R_{M U-C S-Q C S K}=\frac{1}{2} \operatorname{erfc}\left(\frac{3 K+\frac{1}{2}\left(\gamma_{b}\right) \cdot N_{u}^{2}}{\sqrt{\frac{1}{4}\left(9 K^{2}+\frac{7}{4} K^{2} N_{u}^{6}\right)+\frac{1}{2} K^{2} N_{u}^{2}\left(\gamma_{b}\right)+2 K}}\right)
$$

In order to validate the analytical approach of the proposed scheme, an attempt is made through simulations. The next section presents the simulation analysis of the proposed scheme and it is finally compared with the analytical results.

\section{RESULTS AND DISCUSSION}

The BER performance of MU-CS-QCSK modulation scheme is analyzed through Matlab simulation. Simulation parameters taken for the analysis are:

Table 1. Simulation Parameters

\begin{tabular}{|c|c|}
\hline Parameters & Values / Types \\
\hline Chip duration(Tc) & 2 microsecond \\
\hline Symbol duration(Ts) & 2 millisecond \\
\hline Transmission power(P) & $43 \mathrm{dBm}$ \\
\hline Noise power spectral density(No) & $1 \mathrm{dBm}$ \\
\hline Chaotic Mapping Types & $4,8,20$ \\
\hline Spread factor(K) & 100 \\
\hline Total number of users & Rayleigh \\
\hline Fading Channel type & \\
\hline
\end{tabular}


The BER performance of proposed MU-CS-QCSK scheme for various parameters under multipath Rayleigh fading channel is discussed further with the obtained graphs.

\subsection{BER Performance of Multipath Rayleigh Channel}

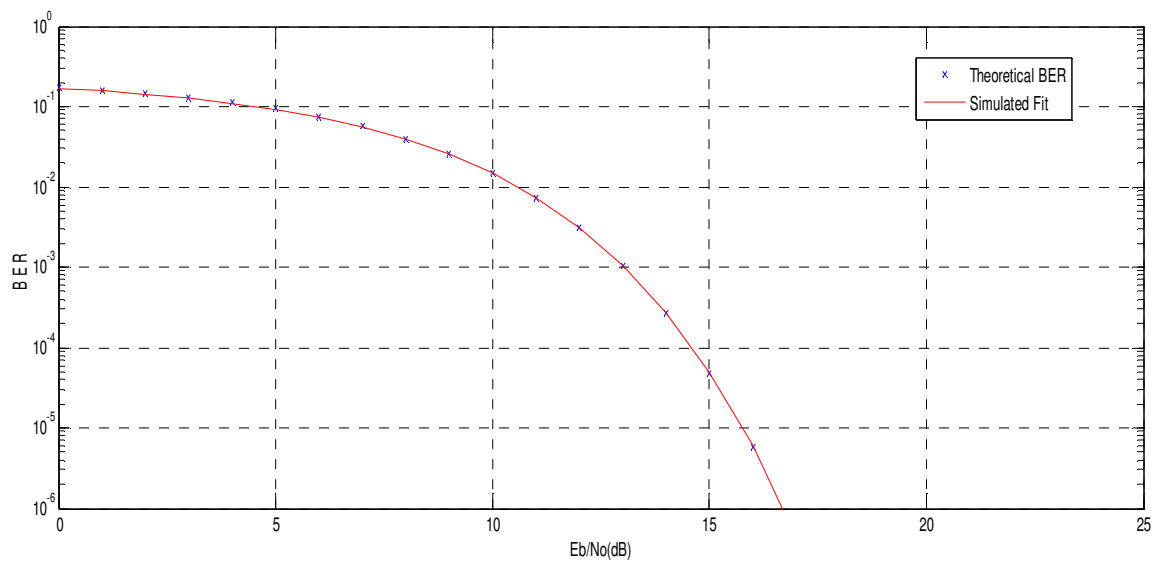

Figure 3. BER performance of MU- CS-QCSK modulation scheme.

From the figure.3, it is inferred that BER performance of MU-CS-QCSK scheme is plotted with the theoretical and simulated values.The BER values calculated from the analytical expression and the simulation are very similar and both the graph merge with each other.For the BER value of $10^{-6}$, the required ( $\mathrm{Eb} / \mathrm{No}$ ) value is $16.5 \mathrm{~dB}$ (approximately).

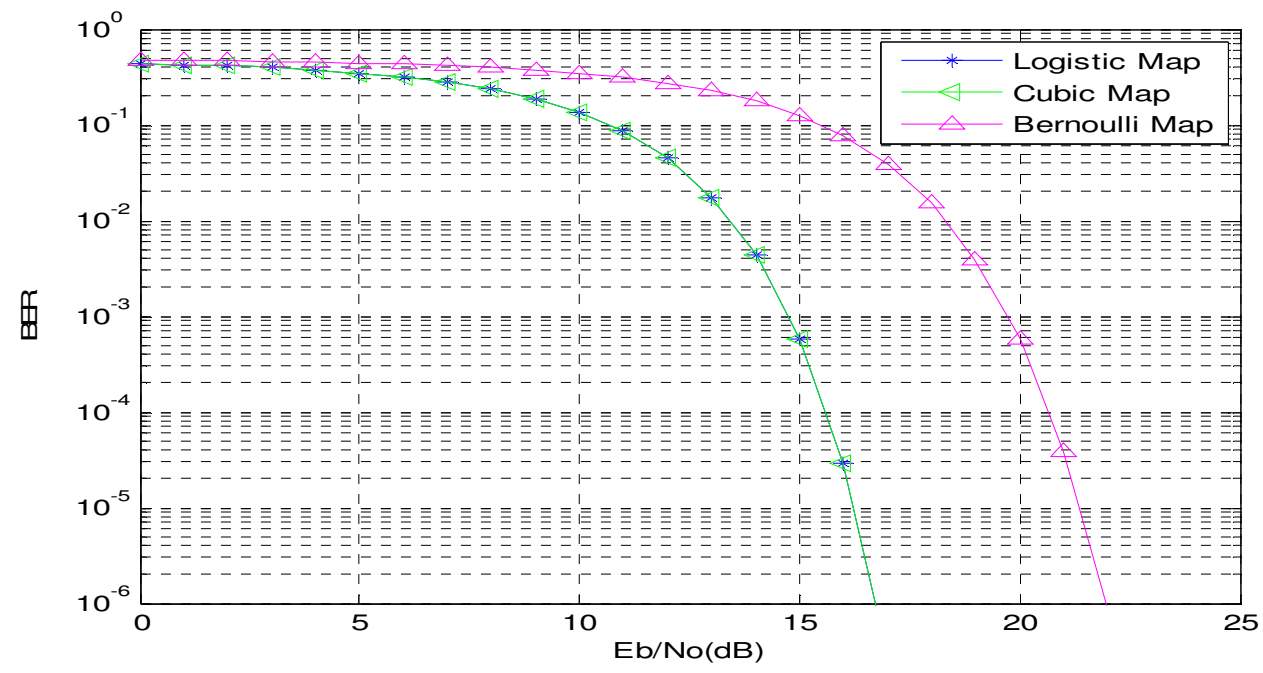

Figure 4. BER performance of MU- CS-QCSK modulation scheme for various chaotic maps

BER performances of MU-CS-QCSK modulation schemes for various chaotic maps were plotted. From the figure, it is inferred that, the logistic map and cubic map has similar and better BER performance compared to the Bernoulli map. For simulation purpose logistic mapping method is used because of its supermacy. 
International Journal of Wireless \& Mobile Networks (IJWMN) Vol. 4, No. 6, December 2012

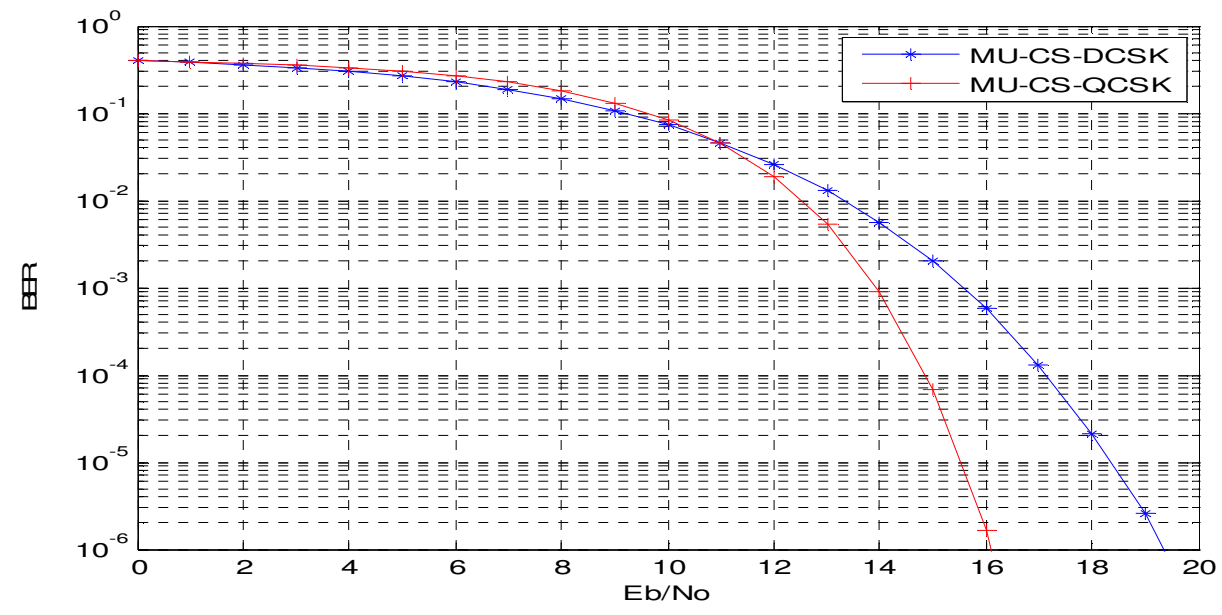

Figure 5. Comparison of BER performance of MU-CS-QCSK modulation scheme

From Figure 5, it can be inferred that, the proposed MU-CS-QCSK scheme offers better BER performance compared to the other multiuser scheme.For the BER of 10-6, the proposed MUCS-QCSK requires16dB(approx) and theMU-CS-DCSK requires19.1dB(approx).

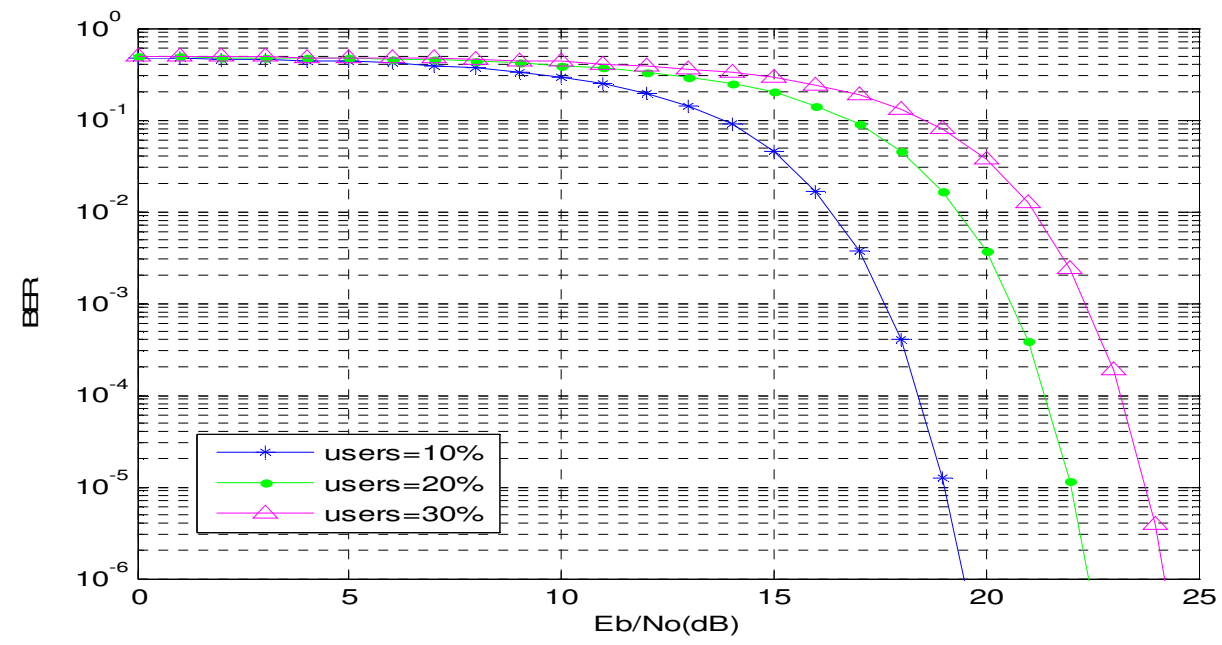

Figure 6. Performance analysis for varying the percentage of users

The BER performance of MU-CS-QCSK modulation scheme for different number of users were plotted. From the graph, it is infered that as the number of user increases the BER performance is limited(i.e) for $10 \%, 20 \%$ and $30 \%$ of the users it requires around $19.1 \mathrm{~dB}, 22 \mathrm{~dB}$ and $24 \mathrm{~dB}$ respectively.This is because, as the number user increases the orthogonality in walsh codes cannot be maintained. 


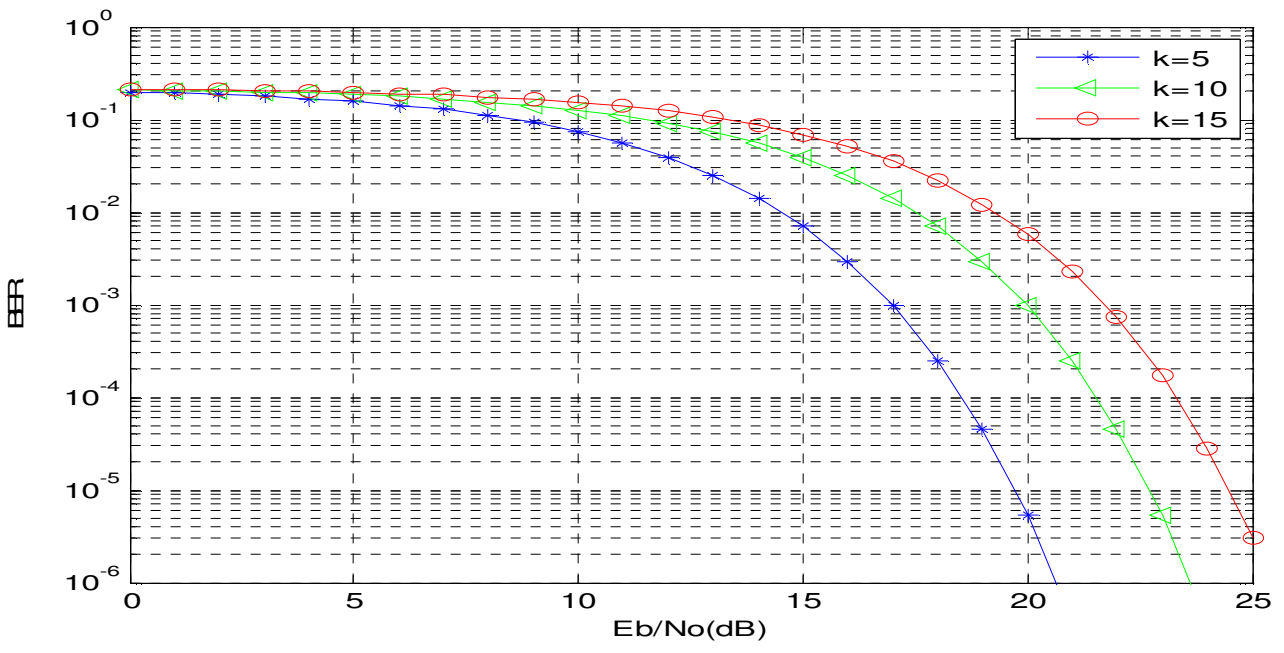

Figure 7. BER analysis under varying Spreading factors

BER performance of CS-QCSK modulation scheme for various spreading factors $(\mathrm{K}=5$, $\mathrm{K}=10, \mathrm{~K}=15$ ) are plotted. Figure 7 . shows that, as the $\mathrm{K}$ value increases the noise performance become worse. In general, smaller Spreading factor corresponds to minimum noise level.

\section{Conclusion}

In the field of chaos-based communication, M-ary DCSK scheme seems to be the best known modulation scheme. But, the drawback is, it requires (N-1) number of delay lines both in the transmitter and the receiver units. In this paper, an improved chaos-based communication method using CS-QCSK technique is recommended for a multiuser scenario. The proposed MU- CS-QCSK scheme, avoids the use of delay lines in the receiver units. It transmits the reference and information signals in the same time slot and offers an increase in data rate, better BER performance and bandwidth efficiency. However, the proposed logic suffers from a marginal increased system complexity. The performance of the proposed modulation scheme is analyzed in a multipath fading channel. Analytical expressions for the BER of MU- CS-QCSK is derived and verified with matlab simulation. Simulation results, shows that the MU-CSQCSK has better BER performance than the other chaos based multiuser modulation schemes. This proves the suitability of the proposed modulation technique for a mobile radio scenario, which is the need of the hour.

\section{REFERENCES}

[1] Abel and W. Schwarz, "Chaos communications-Principles, schemes, and system analysis," Proc. IEEE,vol. 90,pp. 691-710, May 2002

[2] G. Kolumbán, M. P. Kennedy, Z. Jako, and G. Kis, "Chaotic communications with correlator receivers: Theory andperformance limits," Proc.IEEE, vol. 90, pp. 711-732, May 2002.

[3] H. Dedieu, M. P. Kennedy, and M. Hasler,"Chaos shift keying: Modulation and demodulation of a chaotic carrier using self-synchronizing Chua's circuits," IEEE Trans. Circuits Syst. II, vol. 40, pp. 634-642, Oct.1993.

[4] G. Kolumbán, B. Vizvári,W. Schwarz, and A. Abel, "Differential chaos shift keying: A robust coding for chaos communication," Proc. Int.Workshop Nonlinear Dynamics of Electronic Systems, pp. 87-92, June 1996. 
International Journal of Wireless \& Mobile Networks (IJWMN) Vol. 4, No. 6, December 2012

[5] G. Kolumbán, G. Kis, M. P. Kennedy, and Z. Jáko, "FM-DCSK: A new and robust solution to chaos communications," in Proc., Int. Symp. Nonlinear Theory Appl., HI, 1997, pp. 117- 120.

[6] M. P. Kennedy and G. Kolumbán, "Digital communication using chaos,"in Controlling Chaos and Bifurcation in Engineering Systems, G. Chen, Ed. Boca Raton, FL: CRC, 2000, pp. 477500 .

[7] G. Kolumbán and M. P. Kennedy, "The role of synchronization in digital communications using chaos-Part III:Performance bounds for correlation receivers," IEEE Trans. CircuitsSyst. I, Fundamental. Theory Appl., vol. 47, no. 12, pp. 1673-1683, Dec. 2000.

[8] G.Kolumban, Z. Jákó, and M. P.Kennedy, "Enhanced versions of DCSK and FM-DCSK data transmissions systems," in Proc. IEEE ISCAS'99,vol. IV, Orlando, FL, May/Jun. 1999, pp. 475478.

[9] W. M. Tam, Francis C. M. Lau, and Chi K. Tse, "Analysis of Bit Error Rates for Multiple Access CSK and DCSK Communication Systems" IEEE Transactions on Circuits and Systems-I:Fundamental Theory and Applications, Vol. 50, No. 5, May 2003

[10] M. P. Kennedy, G. Kolumbán, G. Kis, and Z. Jákó, "Performance evaluation of FM-DCSK modulation in multipath environments," IEEE Trans.Circuits Syst. I, Fundam. Theory Appl., Vol. 47, No. 12, pp. 1702-1711, Dec.2000.

[11] G. Kolumbán, "Theoretical noise performance of correlator-based chaotic communications schemes," IEEE Trans. Circuits Syst. I, Fundam. Theory Appl., vol. 47, no. 12, pp. 1692- 1701, Dec. 2000.

[12] Z. Galias and G. M. Maggio, "Quadrature chaos-shift keying: Theory and performance analysis," IEEE Trans.Circuits Syst. I, Fundam.Theory Appl., vol. 48, no. 12, pp. 1510-1519, Dec. 2001.

[13] G. Kolumbán and G. Kis, "Multipath performance of FM-DCSK chaotic communications system," in Proc. IEEE Int. Symp. Circuits and Systems, Geneva, Switzerland, May 2000, pp. 433-436.

[14] S. Mandal and S. Banerjee, "Performance of differential chaos shift keying over multipath fading channels," in Proc. Indian Nat. Conf. Nonlinear Systems and Dynamics, Kharagpur, India, Dec. 2003.

[15] Xia, Y.,Tse,C.K.\& Lau, F.C.M, "Performance of differential chaos shift keying digital communication systems over a multipath fading channel with delay spread,"IEEE Trans. Circuits Syst.-II 51,680-684,2004.

[16] G. Kolumbán, P. Kennedy, and G. Kis, "Multilevel differential chaos shift keying," in Proc. Int. Workshop, Nonlinear Dynamics of Electronics Systems, NDES'97, Moscow, Russia, 1997, pp. 191-196.

[17] F. C. M. Lau, M. M. Yip, C. K. Tse, and S. F. Hau, "A Multiple-Access Technique for Differential Chaos-Shift Keying” IEEE Trans.Circuits Syst. I, Fundam.Theory Appl., vol. 49, no. 1, January 2002.

[18] YiWei Zhang, Xubang Shen and Yi Ding, "Design and performance analysis of an FM- QCSK chaotic communication system," International Conference on Wireless Communications, Networking and Mobile Computing, China, pp: 1-4, Sept. 2006.

[19] Jiamin Pan, He Zhang, "Design of FM-QACSK Chaotic Communication System" IEEE trans. Wireless Communications \& Signal Processing, 2009.

[20] Yao,J.\& Lawrance, A.J, “ Performance analysis and optimization of multi-user differential chaos-shift keying communication systems,” IEEE Trans.circ. Syst.-I 53, pp.2075-2091, 2006.

[21] Weikai Xu, Lin Wang and Guanrong Chen, "Performance of DCSK Cooperative Communication Systems Over Multipath Fading Channels”, IEEE Transactions on Circuits and Systems-I: Regular Papers, Vol. 58, No. 1, January 2011 
International Journal of Wireless \& Mobile Networks (IJWMN) Vol. 4, No. 6, December 2012

[22] Lin Wang, Xin Min, and Guanrong Chen, "Performance of SIMO FM-DCSK UWB System Based on Chaotic Pulse Cluster Signals", IEEE Transactions on Circuits and Systems, 2011

[23] Hua Yang and Guo-Ping Jiang, "High-Efficiency Differential-Chaos-Shift-Keying Scheme for Chaos-Based Noncoherent Communication", IEEE Transactions on Circuits and Systems-II: Express Briefs, Vol. 59, No. 5, May 2012

[24] G.Koluban,W.K.Xu and L.Wang, "A Novel differential chaos shift keying modulation scheme," International journal of Bifurcation and chaos,2011,Vol.21,No.3,pp799-814

[25] W. K. Xu and L. Wang, G. Kolumb’an, “A New Data Rate Adaption Communications Scheme for Code-Shifted Differential Chaos Shift Keying Modulation", International Journal of Bifurcation and Chaos, 2012

[26] K.Thilagam and K.Jayanthi, "A Novel chaos based modulation scheme (CS-QCSK) with improved BER Performance", CS\&IT-Computer Science Conference Proceedings, CoNeCo 2012, pp-45-59,October 2012.

\section{Authors}

K.Jayanthi received B.E degree from University of Madras in 1997 and M.Tech degree in Electronics and Communication Engineering and Ph.D from Pondicherry University in 1999 and 2007 respectively. She has 13years of experience in teaching / research. She is currently serving as Associate Professor in Department of Electronics and Communication Engineering, Pondicherry Engineering College, Puducherry. To her credit, she has around 12 journal papers and presented 18 papers in International conferences. Her other areas of interest includes satellite communication, Wireless multimedia networks, Spread spectrum communication, Image processing, etc. She has authored a book on Qos Provisioning in Cellular Mobile Networks.

K.Thilagam received her B.Tech and M.Tech degrees in Electronics and Communication Engineering from Pondicherry Engineering College in 2004 and 2007 respectively. She has 5 years of experience in teaching/research. She is currently pursuing Ph.D in the area of Wireless Communication in Department of ECE from Pondicherry Engineering College, Puducherry. Her research activities are focussed on Cooperative Communication in Cellular Networks, mainly on Modulation and coding techniques.
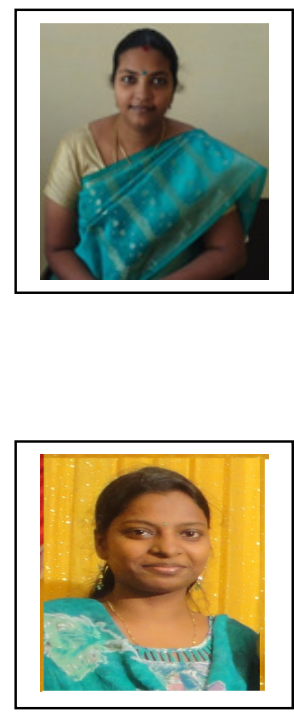